\title{
RAJATABLA: EN EL PROCESO DE LA RENOVACIÓN DE LA NARRATIVA VENEZOLANA DEL SESENTA
}

POR

\author{
Eva KLEIN
}

1. Es ya una tendencia generalizada de nuestra cultura dudar de la univocidad de los acontecimientos históricos y es común encontrar interpretaciones disímiles, a veces hasta opuestas, ante hechos aparentemente simples. La poética moderna traduce de alguna manera esta visión del mundo, fragmentando sus propias historias y proponiendo estructuras artísticas que exigen un compromiso activo por parte del usuario. El hecho de que el lector tenga literalmente que reconstruir el texto para acceder a su significado es el resultado de una estructura literaria que respeta a su receptor y confia en su capacidad de explicarse el mundo sin la necesidad de un narrador que lo lleve de la mano y lo guíe. Pero por otro lado, esta misma estrategia textual suele tener como consecuencia directa la manifestación de múltiples equívocos y malentendidos con respecto a la interpretación de ciertas obras. Esto tal vez explica por qué al revisar un corpus variado de textos ${ }^{1}$ que testimonian la aparición de Rajatabla $(1970)^{2}$ encontramos una gran diversidad de opiniones y conclusiones, muchas veces contradictorias.

Dentro de este heterogéneo material, que consta de artículos críticos, reseñas, comentarios, historias de la literatura ... que registran la recepción del libro, se pueden

\footnotetext{
${ }^{1}$ Orlando Araujo, Narrativa venezolana contemporánea (Caracas: Tiempo Nuevo, 1972). Véase especialmente página 270. Antonio Benítez Rojo, "Rajatabla", Casa de las Américas 64 (La Habana, enero-febrero de 1971). Luis Alberto Crespo, "Rajatabla", El Nacional (Caracas, 20 de abril de 1970). Hoca, "Britto García y Rajatabla", El Nacional (Caracas, 23 de agosto de 1970). Juan Liscano, Panorama de la literatura venezolana actual (Caracas: Tiempo Nuevo, 1972). Véase especialmente páginas 138 y 177. R. J. Lovera De-Sola, "Rajatabla o un proyecto narrativo ambicioso", Zona Franca (Caracas, agosto de 1970). José Ramón Medina, Ochenta años de literatura venezolana (Caracas: Monte Ávila, 1980). Domingo Miliani, Prueba de fuego (Caracas: Monte Ávila, 1973). Julio E. Miranda, Proceso a la narrativa venezolana (Caracas: Ediciones de la UCV, 1975). Véase especialmente página 245 y "Balza, Mata, Britto: un intertexto", Contexto (Caracas). Isaías Peña Gutiérrez, “¿Qué significa Rajatabla?”, El Siglo (Suplemente Cultural) (Bogotá, 7 de febrero de 1971). Carlos Ramírez Faría, "Rajatabla", Revista Momento (Caracas, 4 de agosto de 1970). Fernando Savater, "Una historia despedazada: Rajatabla", Cuadernos Hispanoamericanos 276 (Madrid, junio de 1973).

${ }^{2}$ Luis Britto García, Rajatabla (Caracas: Bárbara, 1970/La Habana: Casa de las Américas, 1970/ México: Siglo XXI, 1971). Nuestras citas textuales pertenecen a esta última edición y sólo indicaremos el número de la página correspondiente.
} 
delimitar dos grandes bloques de opiniones que resumen la diversidad de lecturas frente a la obra de Luis Britto García. Podríamos esquematizar de la siguiente manera los dos bloques:

i Rajatabla es un texto raro y extraño.

ii Rajatabla es un aporte más a la "narrativa de la violencia".

2. Con respecto a los artículos que consideran a Rajatabla un texto "raro" que escapa a toda posibilidad de clasificación.

La recepción inmediata de Rajatabla se sorprende ante su organización formal y eso se traduce en una serie de artículos que al considerar la obra llegan a la conclusión de que se trata de un texto solitario:

Britto García ha escrito un texto aislado, distinto, sin antecedentes ni contactos con otros libros de la actual narrativa venezolana ...

(Alicia Segal)

En su conjunto Rajatabla escapa a cualquier intento convencional de clasificación porque abarca un imposible, una cuarta dimensión en su afán de apuntarle en plena cara a la esquiva realidad...

(Antonio Benítez R.)

Luis Britto García ha incorporado a nuestra ficción ... una actitud personal ... Rajatabla es un libro compuesto sin la "afectación" con que una mayoría de nuestros escritores componen literatura ...

(R. J. Lovera De-Sola)

... el género indefinible de Britto García ...

(José Ramón Medina)

Aunque de manera menos explícita, la reseña de Luis Alberto Crespo reproduce la misma opinión al considerar a Rajatabla una obra que "insiste en la inutilidad de escribirse", y también José Balza, quien arbitrariamente y sin dar razones, rescata seis relatos del libro y juzga el resto como excesivo y tonto. ("Rajatabla es un libro excesivo, hay 67 relatos demás: repeticiones, torpezas, tonterías definitivas ...").

Entre los artículos cortos revisados tal vez la única que logra vincular Rajatabla con otros textos y que no se limita al asombro ante su heterogénea construcción, es el de Isaías Peña Gutiérrez:

Luis Britto García encara la realidad con una filosofía sulfúrica ... Y con un tono narrativo de clara ascendencia kafkiana o kosinskiana, nos sumerge en un mundo donde el símil de los dos espejos que colocados uno frente al otro a sí mismos infinitamente y donde la figura del círculo vicioso ... son los imperantes. Sólo que, para Kafka su mundo se quedó en la angustia existencial y para Britto va hasta la sonrisa consciente (que es válida) de una solución dialéctica para el proceso capitalista.

(Isaías Peña Gutiérrez) 
Ahora bien, al revisar este corpus, que parece apuntar como lugar común hacía lo "raro" de Rajatabla, podemos sacar algunas conclusiones. Dicha apropiación dominante cumple la función de desplazar sin más el difícil problema de una clasificación apropiada de la narrativa de Britto dentro de las tendencias literarias existentes y por ello indica una insuficiencia metodológica. Pero el calificativo de "raro" o "extraño" dentro del contexto de los artículos revisados - con muy pocas excepciones - viene cargado con un juicio de valor positivo que junto con el reconocimiento oficial del Premio Cuento Casa de las Américas (1970) confirma una aceptación entusiasta de la obra. La recepción inmediata de Rajatabla muestra por lo tanto que el calificativo de "raro" viene posiblemente del alejamiento del texto de la estética dominante y de los valores que ella representa. Jauss muestra cómo la revisión de un material del tipo de artículos heterogéneos que registran la recepción inmediata de un texto literario permite ver las relaciones entre la obra y el grado y tipo de aceptación que tuvo y da también información sobre el modelo estético que esta propone:

La manera en que una obra literaria, en el momento histórico de su aparición satisface las expectativas de su primer público, las supera, decepciona o frustra, suministra evidentemente un criterio para la determinación de su valor estético. ${ }^{3}$

3. Con respecto a los estudios que consideran que Rajatabla es un aporte más a la "narrativa de la violencia".

Más que en reseñas o en artículos sueltos, la opinión de considerar Rajatabla un aporte al sistema temático "novela de la violencia", aparece en estudios un poco más largos y especialmente en las historias de la literatura. Los estudios de conjunto de la narrativa nacional o continental exigen más que la descripción o valoración de un texto en particular su ubicación dentro de sistemas literarios mayores y ahí las clasificaciones por temas suele funcionar como una muletilla útil, aunque bastante cuestionable.

Domingo Miliani en Prueba de Fuego, Julio Miranda en Proceso a la narrativa venezolana, Orlando Araujo en Narrativa venezolana contemporánea (6) y Juan Liscano en Panorama de la literatura venezolana actual (7) parecen tener un común acuerdo en incluir la narrativa de Britto dentro del sistema de la violencia. De esta manera, el subsistema "narrativa de la violencia" conjuga a todo tipo de narradores, de las tendencias más diversas y se convierte en una categoría tan amplia que es aplicable a casi todo y termina diciendo muy poco de las obras en sí. "Narrativa de la violencia" por ser un sistema fundamentado en afinidades temáticas excluye, o al menos subalterna, elementos tan importantes como las perspectivas de enunciación o las estrategias textuales. Sólo así se explica que escritores de propuestas tan disímiles como Luis Britto y José Balza entren en la misma clasificación. Si bien el criterio temático funciona como un importante eje organizador — novela indigenista, novela de la revolución mexicana, etc.- no nos queda clara su operatividad y suponemos que hay muchas obras que se le resisten. Sería inapropiado hablar de Rajatabla como un texto cuyo tema principal es la violencia puesto que su propuesta temática es

\footnotetext{
${ }^{3}$ Hans Robert Jauss, "La historia literaria como desafio a la ciencia literaria", La actual ciencia literaria alemana (Madrid: Anaya, 1971).
} 
múltiple y en todo caso habría que hablar en ella de las violencias. La lucha guerrillera o la violencia represiva de las cárceles, de modo directo y explícito como por ejemplo en Entre las Breñas o en Se llamaba S.N., casi no se da en Rajatabla y si bien la obra sí denuncia agresiones, difícilmente se le puede clasificar con un criterio reduccionista como el de un sistema temático.

Carlos Pacheco, quien ha trabajado la "narrativa de la dictadura" (en base a nucleos temáticos), advierte que la discusión sobre la validez del criterio es pertinente y está aún sin solución definitiva. ${ }^{4}$ Otro joven crítico venezolano, Alberto Rodríguez, señala que una de las deficiencias más notables del desarrollo de la historiografia literaria es precisamente la utilización de criterios regionales o temáticos:

Entre los obstáculos principales detectados en el discurso de la historiografía literaria de nuestra América se encuentran: ... la atomización o disgregación del conjunto literario latinoaméricano, debido a la utilización de criterios regionales o temáticos ... el reduccionismo de pretensiones homogeneizadoras, que prescinde de la pluralidad étnica, lingüística, social y cultural, desconociendo su papel como factor distintivo que incide en la producción literaria. ${ }^{5}$

\section{Apuntes sobre la estructura de Rajatabla.}

La recepción inmediata de Rajatabla se sorprendió ante la estructura polifacética del libro y por ello no logró vincularlo con el contexto literario en el que la obra se produjo.

Evidentemente, Rajatabla es un texto heterogéneo que yuxtapone una sorprendente diversidad de códigos, temas, puntos de vista, estilos ... su distribución en siete partes, aparentemente irregulares, sin evidentes lazos de unión y subdivididos a su vez en un número irregular de narraciones cortas, hace pensar en un caos narrativo que no es tal cuando se revisa el libro con más rigor.

La primera parte, Carne, la constituyen los textos más directamente relacionados con una actualidad nacional: barrios marginales ("La Calle"), niños víctimas de la miseria de la ciudad ("Helena" y "Carne"), el absurdo de un espacio urbano que permite la convivencia simultánea de un picnic (que connota paz y tranquilidad) y un asesinato realizado por los agentes oficiales de la policía ("Picnic interrumpido"), varios cuentos que remiten a la violencia urbana ("Bomba" o "Usted puede mejorar su memoria"), un texto que muestra los niveles de alienación de un sector social a través de ídolos comercializados (Musubay o José Gregorio Hernández) y finalmente, el último texto de esta parte ("Muerte de un rebelde") cierra este primer ciclo y a la vez anuncia ya con claridad la perspectiva ideológica del libro como totalidad. Esta breve narración que cuenta la agonía de un rebelde termina diciendo:

Cáceres murió sin ver la revolución (32).

\footnotetext{
${ }^{4}$ Carlos Pacheco, La narrativa de la dictadura como sistema temático de la literatura hispanoamericana (sin publicar).

${ }^{5}$ Alberto Rodríguez C., "Marginalidad de la literatura colonial en Venezuela", Araisa (Caracas: Celarg, 1976-1982) 116.
} 
Con ello el narrador, aunque con un dejo de humor negro, introduce la posibilidad de un cambio, de una posible revolución por venir, a la vez que a través de la descripción de las atenciones que recibe el enfermo de sus "camaradas" (el narrador o de Aguirre) el texto ilustra el funcionamiento de una célula más o menos organizada que está trabajando en alguna meta política. Se muestra tambíen la existencia de una lucha activa: "La radio hablaba de bombardeos en alguna parte" (31) y de una organización represiva: “... porque a la gallega que venía a barrer dos veces a la semana hubo que despedirla para no tener que explicarle quién era el señor en pantuflas, las precauciones, conversar de política pero sin entrar en detalles no fuera uno a enterarse de que nunca abriera la puerta no fuera a ser cosa también de que" (30). "Muerte de un rebelde" al plantear las posibilidades de un cambio revolucionario viene a ser una respuesta a los ocho textos anteriores de Carne que denuncian una situación social paupérrima.

Sintetizando, Carne introduce los aspectos de denuncia sobre la violencia policial, la violencia guerrillera, la represión, la marginalidad y la resistencia rebelde, y si a estos ejes temáticos le agregamos el primer cuento de Calle ciega ("Utopía") que introduce un discurso que podría llamarse de ciencia-ficción tenemos armado en parte el mosaico de significados de Rajatabla.

Calle ciega viene a desarrollar el mundo equivocado, "ciego" y sin salida hacia el cual avanza vertiginosamente una sociedad mecanizada y controlada por alta tecnología. "Gerontia" es un mundo absurdo donde no hay organizaciones clandestinas, ni irresponsables, ni hombres felices ... todo está unificado en una vejez sin sentido, cuyo universo de acción se reduce a una silla de ruedas, y hacia el mismo significado apuntan "Cualidades", "Transformación" y "Pasado". "Lope" se sale de la línea de denunciar un mundo futuro incoherente para insertar una lectura no oficial del pasado. Lope (Lope de Aguirre), lejos de ser el violento y sanguinario tirano que quedó registrado en la mayoría de los textos de historia, en estas páginas pasa a ser un consciente luchador en busca de una fracasada emancipación. Con esto sólo sigue la línea general de Calle ciega de mostrar universos que van en una dirección inhumana y autodestructiva. Si bien "Lope" remite a un tiempo pasado y el resto de los cuentos de Calle ciega más bien apuntan hacia el futuro, todas son lecturas no oficiales del proceso histórico y denuncias de actitudes socio-políticas que llevan a resultados indeseables.

Trono potencia más que las dos partes anteriores los niveles de vuelo imaginativo y todos sus cuentos parecen vincularse con problemas de poder, dados a través de diversos registros de discursos fantásticos y un tono alucinante. La narración "Tormentos" hace una enumeración progresiva de las torturas más refinadas y exageradas que mente alguna pueda diseñar y en su penúltima versión invoca especialmente al lector:

El preso, a quien como a ti, se daba a entender desde su nacimiento que lo que lo rodeaba era el mundo de la verdad, y no lo que es realmente, el recinto cerrado de una prisión colosal (92).

No deja de ser significativo que esta prisión que es metáfora de toda la humanidad que vive en un mundo donde las verdades están encubiertas, atrapadas en la cárcel del lenguaje, está señalada como uno de los suplicios más terribles y la propuesta de Rajatabla 
es justamente romper esa "prisión colosal" y mostrar una posibilidad distinta de "la verdad", una "lectura" nueva del mundo.

Ilusiones ópticas reúne once narraciones todas relacionadas con problemas de escritura o de arte, siempre con registros diversos y muchas veces con fuerte ironía. En estos textos - y en muchos otros del libro- se instaura la coexistencia de dos niveles de narración mutuamente excluyentes: la historia explicíta por un lado y la historia implícita que el lector debe deducir, de manera que la lectura comprensiva rechaza por falsa la versión expresamente contada por el narrador. Así, "Artes posibles" son contrariamente a lo que anuncia el título un ejercicio enumerativo de las artes imposibles, "La culpa no es mía" intenta mostrar la responsabilidad del hombre al dejarse atrapar en un uso limitado de palabras, "Libros" es nuevamente una enumeración, pero de obras imposibles, "Primer manifiesto de arte realista" es una manifestación que niega todo arte, y así sucesivamente

Trama está formado por apenas seis textos que parecen apuntar a cuestionar algunas convenciones sociales centrales que organizan nuestra civilización: el matrimonio ("Amo amas") el pensamiento lógico ("Locura"), los valores de moral dominante ("El extraño caso"). En "Sueño", se narra como una aterradora pesadilla la construcción de un mundo que es exactamente el nuestro:

... la sirena, el trabajo, la jerarquía, la muerte y el hambre

de tu irremediable realidad y de tu vida irremediable (151)

Así Trama, al igual que Carne, es una lectura crítica de nuestra actualidad.

Vuelco y Ciclo son las dos últimas partes de Rajatabla y organizan, dentro de la apertura temática y variedad de registros ya señalados, un mundo donde la ciencia, la computadora, la máquina posee cadz vez mayor control, hasta llegar a la paradójica situación en que la ciencia resuelve todos los males materiales del hombre (hambre, frío, enfermedades ...), sólo que descuida hasta tales niveles su humanidad y sensibilidad que termina convirtiéndolo en una especie de robot, perfectamente programado. Además la vida (a pesar de que en el mundo ya no hay ni enfermedades ni muertes) ya no tiene sentido:

En efecto, el cerebro humano también dejó de ser necesario, también se atrofió y también acabó por desaparecer (173).

"Cibernia" es la narración que lleva hasta sus últimas consecuencias la constitución de un mundo regido por cerebros artificiales. Es una utopía al estilo de Un mundo feliz de Huxley o 1984 de Orwell, sólo que todavía mucho más desesperanzado. Prevé la muerte del universo entero y en esas condiciones en la tierra todo se vuelve inútil y es indiferente hacer o dejar de hacer cualquier cosa. La perspectiva de la narración es sumamente crítica con relación al universo que describe, y así el texto pasa a ser una denuncia de ciertas tendencias de organización político-social que arrastran al hombre hacia un sistema donde la técnica domina y la humanidad agoniza.

En este alucinante, aséptico y super-organizado mundo la gente está hastiada de ser "feliz" y se destruye a sí mismo con explosivos. El protagonista, que asume la historia en primera persona, reconoce un desesperado deseo de estar insatisfecho de algo pero el 
psicológo interviene y en un tratamiento de diez minutos le extirpa tales ideas (182). En este "perfecto" mundo, las sensaciones más primarias también se controlan electrónicamente:

Corrientes de adecuada intensidad puestas a circular por los nervios respectivos producían las mismas sensaciones placenteras que ... el estar vertiendo células germinativas con tractos esterilizados ... (187).

Las siete partes que organizan Rajatabla tienden a armar un mosaico donde a pesar de la heterogeneidad de códigos, tramas y narradores se da la construcción de un texto coherente. Si bien las narraciones se dan con relativa autonomía y hay una desaparición total de un narrador que asuma la unificación de la obra, sin embargo el humor, la perspectiva crítica y el cuestionamiento de la historia oficial conforman un denominador común. En este sentido, Rajatabla es una clase de "novela-testimonio", puesto que es portavoz de las personas sin historia y no se limita a ser "objetivo", sino que lleva del brazo de la investigación sociológica la imaginación literaria. Frente a las propuestas del tipo de las "non-fiction novels" de Capote o el testimonio riguroso de Oscar Lewis, Britto opta por un camino más amplio que se vincula con propuestas como, por ejemplo, las de Miguel Barnet, quien considera que la novela testimonio debe aprovechar de la fantasía para cumplir una función estética y también practica y así, colaborar con la definición cultural de América Latina. $^{6}$

Más que caos, existe entre las diversas partes del libro una profunda imbricación de temas y una propuesta estético-ideológica totalizadora bastante compleja. Rajatabla está unificado por el título que viene a funcionar como un llamado de atención con respecto a la organización del discurso. "A rajatabla" significa decir o hacer las cosas cueste lo que cueste, a todo trance y sin contemplaciones. De ahí que la intención del hablante básico, en cuanto a organizador último del discurso, es expresar algo a como dé lugar. Posiblemente, una realidad compleja y heterógenea difícilmente podría ser descrita con un lenguaje transparente y un contenido unívoco. Era imprescindible que Rajatabla abriera un abanico de posibilidades temáticas, de códigos y de perspectivas narrativas para describir el complejo universo al que remite, era imprescindible forzar el lenguaje, las categorías lógicas y los espacios estancos de los géneros.

Sin embargo, esa heterogeneidad o complejidad no significa un caos sino un orden diferente y está en función de la cantidad de información que la obra busca transmitir.

La información, tal como lo define la ciencia de la comunicación, es una cantidad sumada, es algo que se añade a lo ya conocido y se presenta como adquisición original. De este modo, un mensaje que comunica contenidos que el receptor ya espera o presupone, y no le plantea extrañamiento ni en su contenido ni en su grado de organización, transmite una cantidad de información inferior a aquel discurso que se organiza de un modo particular.

Cuanto más ordenado y comprensible es un mensaje tanto más "previsible" resulta: los mensajes de felicitaciones navideñas, o los de pésame, que siguen criterios de probabilidad

\footnotetext{
${ }^{6}$ Miguel Barnet, "La novela testimonio: socioliteratura", Unión (La Habana, 1969) 99-122.
} 
muy limitados, son de significado muy claro, pero nos dicen poquísimo que no supiéramos ya. ${ }^{7}$

Dentro de un modelo estético que busca el asombro del receptor y que lleva los cortes y cambios de los registros de lenguaje a niveles lúdicos, así como la diversidad temática y de perspectivas de narración a una amplisíma gama de posibilidades, Rajatabla instaura un sistema de comunicación entre emisor y receptor que por resultar imprevisible página tras página transmite una gran cantidad de información sobre Venezuela.

Un texto es un sistema de probabilidades donde ciertos elementos particulares de "desorden" aumentan su capacidad comunicativa.

El lenguaje cotidiano, sobre el que la mayoría de los textos de Rajatabla están armados, funciona justamente con expresiones que se oponen a las rígidas normas gramaticales y sin tácticas y por ello nos comunican informaciones nuevas con una síntesis extrema. A lo que nos interesa llegar es a mostrar que la desorganización introducida en Rajatabla no es de ninguna manera un caos narrativo - si lo fuera, su significado sería incomprensiblesino que es un orden nuevo, no habitual y particular a esta propuesta poética. Eco muestra que los relativos desórdenes que el discurso literario introduce en la lengua aumentan el número de significados posibles, la ambigüedad y la polisemia.

Por lo demás este descubrimiento no es nuevo, ya los formalistas rusos, especialmente Shklovski (hacia 1917), disertaban sobre los efectos de "desautomatización" del discurso artístico. El aludido "caos" de Rajatabla es un desorden respecto a organizaciones narrativas diferentes o anteriores, pero es un riguroso orden dentro de los parámetros asumidos por este texto y además es contenido puesto que remite a un mundo complejo y conflictivo que no encuentra otro modo mejor de expresión.

5. ¿Hacia dónde apunta esta propuesta?

El humor como elemento desestabilizador junto con una férrea crítica a las convenciones y al stablishment son tal vez las líneas dominantes de Rajatabla en cuanto a su propuesta ideológica. Varias narraciones desarrollan una constante denuncia de una hecatombe final, una destrucción. No puede desecharse sin embargo, que este desencanto se da parodiado, cuestionado y en contraposición a una posibilidad remota de cambio. Si bien se anuncia el fallecimiento de la humanidad entera (50) y la tendencia del universo a la destrucción ("Entropía" o "La forma de la tierra"), el libro intercala textos de una posible apertura hacia realidades distintas. En el irónico relato "Nada de negocios", queda abierta la posibilidad de una revolución que da la espalda a Mr. Godwin y lleva al "bienintencionado" Presidente de la República, que se desvivía por "desarrollar el clima de confianza para las inversiones" (80), ante un alto tribunal. El final de la narración deja como alternativa un juicio. Otro texto como "El Presidente amaneció de buen humor" se inscribe dentro de la misma línea de apertura hacia una justicia social: "se nacionalizan las industrias básicas ... se expropian los latifundos ... se afianza la soberanía” (81).

Las narraciones de ciencia-ficción denuncian la dirección hacia la cual avanzan los países desarrollados en su total desatención a valores humanos primarios como los sentimientos, la sensibilidad o las relaciones afectivas. Los cerebros electrónicos que

\footnotetext{
${ }^{7}$ Umberto Eco, Obra abierta (Barcelona: Seix Barral, 1979) 135-192.
} 
Britto prevee parecen mostrar una tendencia de las sociedades superorganizadas y superindustrializadas hacia el control esclavizado del cuerpo junto con una racionalidad metálica. La sensualidad posible pasa a ser un ejercicio calculado, el culto al cuerpo joven (todo el mundo se conserva dentro de ciertos patrones limitados de edad y nadie muere "Futuro") sólo tiene como objetivo su propia anulación puesto que desaparece la investidura erótica y la sensibilidad. Todos los hombres parecen asexuados, mecánicos y producidos en serie. Britto García, escritor sorprendentemente consciente de sus propias búsquedas y de sus logros, ha manifestado que Rajatabla es una especie de denuncia del agotamiento de la cultura occidental junto con un llamado de atención hacia la necesidad de un proyecto coherente para Venezuela y Latinoamérica. Proyecto para cuya construcción es indispensable aprovechar la relativa juventud de nuestro continente y unir esfuerzos:

Rajatabla era un intento de entender el país, y aun más de entender Latinoamérica, porque a mí me da la impresión de que tanto Venezuela como América Latina es un ser que todavía está al encuentro de su conciencia, al cual todavía le falta encontrarla ... Tengo la impresión de que a nivel mundial las soluciones culturales del primer mundo están a punto de agotarse, ellos han avanzado en función de una cultura meramente tecnológica, que se presiente encaminada hacia un callejón sin salida; el segundo mundo se ha nutrido de las reacciones muy particulares a esa cultura ... El mundo está actualmente enfrentado a una crisis existencial y cultural en la cual es muy probable que una identidad todavía sin definir como la de América Latina pueda postular una solución. ${ }^{8}$

6. Relaciones de Rajatabla con el resto de la narrativa venezolana y latinoamericana de la década de los años sesenta. Enrique Pupo-Walker considera que a pesar de que la crítica no ha destacado con claridad necesaria el lugar que corresponde al cuento en el desarrollo y apogeo de la narrativa latinoamericana se puede afirmar que la superación formal de la narrativa de los últimos decenios se ha llevado a cabo precisamente en sus moldes opresores. ${ }^{9}$

El libro de narraciones que como Rajatabla se enfrenta a la constitución de los generos en cuanto compartimentos estancos, lleva su discurso a un terreno inseguro e intermedio. Si bien en Venezuela esta búsqueda se presenta como novedad en América Latina ya tenía una trayectoria. Borges, con su Historia universal de la infamia (1935) y con Ficciones (1944), ya apuntaba hacia el terreno donde el libro de cuento se presenta como conjunto organizado de narraciones cortas y donde la autonomía de los textos es sólo relativa. $E l$ llano en llamas (1953) de Rulfo, Bestiario (1951) de Cortázar, o Hijo de hombre de Roa Bastos también ilustran este tipo de narración donde hay una relación estrecha entre textos cortos que a su vez gozan de unidad de sentido. Estos libros desatan también las potencialidades de la imaginación, exploran el lenguaje con una clara relación iconoclasta hacia ella y abren las posibilidades de la narración a un amplio repertorio de temas y técnicas. En todos estos aspectos Rajatabla viene a ser una lograda continuación de caminos que se vienen marcando desde hace muchos años en la literatura latinoamericana. Al

\footnotetext{
${ }^{8}$ En entrevista inédita a Luis Britto García realizada por Francisco Javier Lasarte.

${ }^{9}$ Enrique Pupo-Walker, "Notas sobre la trayectoria y significación del cuento hispanoamericano", El cuento hispanoamericano ante la crítica (Madrid: Castalia, 1973) 1-21.
} 
mostrar estas necesarias relaciones, no tratamos de verificar influencias sino de precisar otra de las fases del trabajo de Britto: su elaboración de discursos de variado origen como el publicitario, periodístico, literario, histórico ... todos parodiados, muestra justamente un diálogo con obras diversas.

Rajatabla parte de la nueva novela latinoamericana y recupera su experiencia para asumir las posibilidades de una mirada que muestre una realidad deteriorada, llena de fantasías y de ambigüedades.

En cuando a la ubicación dentro del proceso del desarrollo de la literatura venezolana, Rajatabla es tal vez la respuesta más acabada a los intentos que se vienen dando aproximadamente desde 1959 con los grupos "Sardio", "Tabla Redonda" y "El Techo de la Ballena". Todos fueron intentos que en cuanto modelos estéticos significaron búsquedas estructurales para quebrantar los moldes de la racionalidad tradicional y del concepto establecido de belleza.

El contexto social en que se escribe la narrativa de la década del sesenta indudablemente influye - aunque de modos diferentes - sobre los escritores . En este sentido, habría que tomar en cuenta elementos como el crecimiento caótico de Caracas y la prolongada violencia sostenida y diversificada que entre 1945 (derrocamiento de Isaías Medina Angarita) y 1974 (culminación del período de Rafael Caldera) vive el país. (Violencia que por lo demás no es nueva y viene manifestándose casi continuamente desde el período colonial.)

La producción literaria nacional a principios de los años sesenta se mantiene dentro de una dualidad: incorpora modelos narrativos renovadores que vienen de las vanguardias, se apropia de sus propuestas estéticas y técnicas y a la vez desarrolla una mirada propia, altamente critica. Al Sur del Equanil (1963) de Renato Rodríguez es una obra que ilustra estas búsquedas y que por su desarrollado sentido del humor se vincula estrechamente con Rajatabla. Por otro lado, País portátil (1968) que representa una nueva lectura de la historia de Venezuela desde las luchas por la emancipación hasta la rigurosa contemporaneidad de uno de los narradores (Andrés Barasarte), rescata una visión del proceso de desarrollo del país donde la violencia y lo afectivo explican los cambios. País portátil introduce en su escritura alternancia de narradores y cambios espacio-temporales, técnica con la cual Rajatabla también va a trabajar. En La mala vida (1968), de Salvador Garmendia, se narra una historia homogénenea a través de una sola voz y en ese sentido el texto entra en conflicto con la heterogeneidad propuesta por Rajatabla, pero sin embargo en algunas páginas de denuncia de lo absurdo y sin sentido de ciertas actividades humanas, las dos obras coinciden.

La tendencia más radicalmente opuesta al proyecto estético-ideológico de Britto se encuentra representado en los escritos de José Balza. Este último representa la visión europeizante con ambiciosas búsquedas formales y una visión desencantada que niega con radicalidad toda posibilidad de cambio. La narrativa de Balza, si bien en algunos casos trabaja sobre el tema de la violencia (en Largo - 1968 - hay una vaga referencia a la preparación y realización de un asalto revolucionario y en "Un libro de Rodolfo Iliackwood" (1964) se menciona la muerte de un joven guerrillero), éstos se dan encubiertos en un lenguaje de difícil penetración y planteados como simples elementos cotidianos sin trascendencia. Britto, como ya lo hemos señalado, opta por un camino de denuncias críticas donde constantemente se invoca un lector consciente que cuestione los valores establecidos, 
la historia oficial, y así intervenga en el diseño de una nueva estructura social. En Abrapalabra (1980), este planteamiento ideológico sigue vigente y se concreta en la persona de Rubén, quien a pesar de los fracasos (inclusive muere y revive) sigue luchando por un mundo más coherente.

Sin bien hay algunos rasgos tipificadores en la narrativa de la década de los años sesenta, es necesario ser cuidadoso en su formulación para no proponer rótulos que por amplios y generalizados unifiquen bajo su signo propuestas tan diversas como las de Britto, Balza o Abreu. Toda unificación homogeneizadora debería verse con sospecha puesto que estaría en función de un modelo reduccionista de visión mutiladora que ignora las variantes culturales y que liquida — por intereses ideológicos - la diversidad existente en nuestro país. 
